\title{
Avaliação do ciclo de vida da construção civil habitacional brasileira
}

\author{
Life cycle assessment of Brazilian civil housing construction \\ Evaluación del ciclo de vida de la civil residencial en Brasil
}

Recebido: 04/01/2022 | Revisado: 09/01/2022 | Aceito: 14/01/2022 | Publicado: 15/01/2022

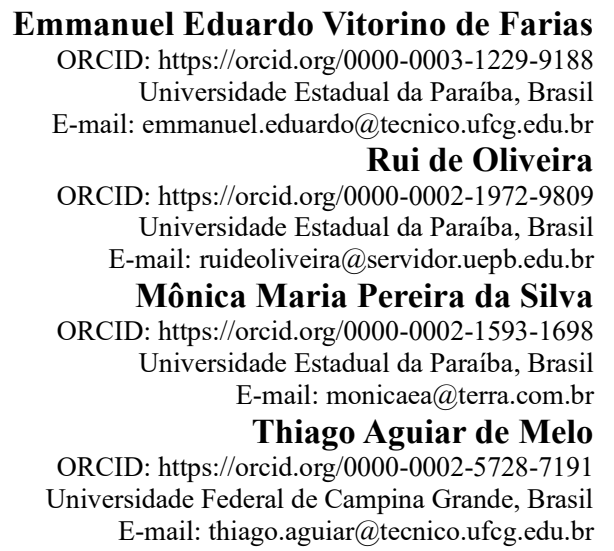

\begin{abstract}
Resumo
A construção civil habitacional demanda grande quantidade de recursos naturais, gerando danos significativos ao meio ambiente. O presente trabalho tem como objetivo quantificar os impactos ambientais potenciais negativos dos insumos mais relevantes usados na construção de edificações residenciais por $\mathrm{m}^{2}$ de área construída. Para representar as construções mais usuais no Brasil, foram utilizados como referência para os cálculos de insumos, três projetos residenciais padrão popular, empregados em programas habitacionais governamentais, com número de pavimentos e métodos construtivos distintos. Os impactos ambientais potenciais negativos foram estimados utilizando a metodologia Avaliação do Ciclo de Vida. Os resultados demonstram que os maiores impactos ambientais negativos, estão relacionados às edificações com mais de um pavimento, sobretudo em função do uso do cimento Portland e do revestimento cerâmico. Por fim, o presente estudo, fornece informações que auxiliam a tomada de decisão, na elaboração de projetos de arquitetura, nos processos construtivos e na aquisição de materiais de construção, visando minimizar os impactos ambientais potenciais negativos.
\end{abstract}

Palavras-chave: Sustentabilidade; Impactos ambientais; Construção civil residencial.

\begin{abstract}
Housing construction requires a large amount of natural resources, causing significant damage to the environment. This work aims to quantify the potential negative environmental impacts of the most relevant inputs used in the construction of residential buildings per $\mathrm{m}^{2}$ of built area. To represent the most common constructions in Brazil, three popular standard residential projects, employed in government housing programs, with different floors and construction methods, were used as a reference for input calculations. Potential negative environmental impacts were estimated using the Life Cycle Assessment methodology. The results show that the greatest negative environmental impacts are related to buildings with more than one floor, mainly due to the use of cement and ceramic coating. Finally, this study provides information that helps decision-making, the elaboration of architectural projects, construction processes and the acquisition of construction materials, aiming to minimize potential negative environmental impacts.
\end{abstract}

Keywords: Sustainability; Environmental impacts; Residential civil construction.

\section{Resumen}

La construcción civil residencial requiere una gran cantidad de recursos naturales, provocando importantes daños al medio ambiente. Este trabajo tiene como objetivo cuantificar los potenciales impactos ambientales negativos de los insumos más relevantes utilizados en la construcción de edificios residenciales por $\mathrm{m}^{2}$ de área construida. Para representar las construcciones más comunes en Brasil, se utilizaron como referencia para los cálculos de entrada tres proyectos residenciales estándar populares, utilizados en programas de vivienda del gobierno, con diferentes pisos y métodos de construcción. Los impactos ambientales negativos potenciales se estimaron utilizando la metodología de Evaluación del Ciclo de Vida. Los resultados muestran que los mayores impactos ambientales negativos están relacionados con edificaciones de más de un piso, principalmente por el uso de cemento y revestimiento cerámico. 
Finalmente, el presente estudio aporta información que ayuda a la toma de decisiones, en la elaboración de proyectos arquitectónicos, en los procesos constructivos y en la adquisición de materiales de construcción, con el objetivo de minimizar los potenciales impactos ambientales negativos.

Palabras clave: Sustentabilidad; Impactos ambientales; Construcción civil residencial.

\section{Introdução}

A construção civil é uma atividade econômica que gera muitos empregos tanto diretamente, como indiretamente. Os seus resultados garantem conforto e bem-estar à população. Entretanto, para viabilizar estes benefícios, a indústria da construção civil demanda muitos recursos naturais, destacando-se o consumo de água potável, com 16,6\% do consumo global, madeira de reflorestamento, com 25\% e metais e energia com 40\% (Guggemos \& Horvath, 2005). O cimento Portland dos impactos ambientais negativos gerados por essa atividade, permite tomar iniciativas para aprimorar os meios de produção, os métodos construtivos e a escolha de matérias para minimizar os impactos (Asadollahfardi et al., 2015).

No Brasil, existe um déficit habitacional de 7,7 milhões de moradias (FGV, 2018), que corresponde a 11\% do número de residências existentes (IBGE, 2015). Atualmente, muitas famílias não podem arcar com aluguéis, sendo obrigadas a habitarem imóveis em condições precárias, geralmente em áreas de risco, afetando a sua saúde e segurança. Devido a estes fatores, há uma tendência de aumento na demanda por novas construções habitacionais nos próximos anos.

Segundo Montes (2016), os programas habitacionais brasileiros, especialmente o Programa Minha Casa Minha Vida (PMCMV), não levam em consideração impactos ambientais negativos na concepção dos projetos, escolha dos materiais e execução da obra. Comumente os projetos são replicados em vários estados brasileiros com bioclimas distintos, negligenciandose as suas particularidades. Este fato prejudica inclusive a eficiência energética na utilização do imóvel ao longo de sua vida útil, que conforme a Norma Técnica Brasileira NBR 15575-1 (ABNT, 2013), é de 50 anos.

Para superar o déficit habitacional no país, é necessário construir moradias e investimento do governo em programas habitacionais. É explícito que esse setor da economia tenda a crescer, como os impactos ambientais negativos não são levados em conta na elaboração do projeto, nem na escolha de materiais e métodos construtivos, determinar quais os impactos ambientais negativos causados pelos insumos relevantes é a primeira iniciativa para aprimorar os projetos e a indústria da construção civil, visando reduzir ou mitigar os danos ambientais.

Neste contexto, a sustentabilidade na construção civil é um tema abrangente, que vai desde a concepção dos projetos, preparação do terreno, fabricação dos insumos, passando pela execução da obra, sua utilização, até sua demolição, reciclagem, tratamento dos rejeitos e descarte.

Segundo a ABNT NBR ISO 14040, a Avaliação do Ciclo de Vida (ACV) é uma metodologia para avaliar os potenciais impactos ambientais ao longo de todo o ciclo de vida de um produto, do berço ao túmulo, de forma quantitativa (ABNT, 2014). Ela é uma ferramenta eficaz de análise ambiental na construção civil, por englobar a análise de impactos desde o projeto até a demolição, reciclagem e descarte.

Há vários estudos e aplicações da ACV para a construção civil habitacional. Guggemos e Horvath (2005) aplicaram a ACV comparativa de dois edifícios, um em estrutura metálica e outro em estrutura de concreto armado, constatando que a edificação em concreto armado possui mais emissões relacionadas ao uso de energia, as mudanças climáticas $\left(\mathrm{CO}, \mathrm{CO}_{2}\right)$, bem como $\mathrm{NO}_{2}$, material particulado, $\mathrm{SO}_{2}$ e emissões de hidrocarbonetos e transporte e na estrutura de aço, observaram maiores emissões de compostos orgânicos voláteis e metais pesados $(\mathrm{Cr}, \mathrm{Ni}, \mathrm{Mn})$, nas fases de pintura, uso de maçaricos e soldagens. Aktas e Bilec (2011) estudaram a relação entre o tempo de vida dos edifícios nos resultados da ACV, demostrando que a vida útil média das edificações residenciais nos EUA é de 61 anos, com tendência de crescimento linear. Além disso, a razão entre o consumo energético da renovação interior e do ciclo de vida da edificação é da ordem de 3,9\% para residências regulares e 7,6\% para residências de baixo consumo de energia. Tae et al., (2011) verificaram por meio da ACV que houve redução do consumo 
energético e emissões de $\mathrm{CO}_{2}$ ao aumentar a resistência do concreto. Heede e Belie (2012) analisaram os impactos ambientais com concreto fabricado com escória de alto-forno, e concluíram que os impactos ambientais são menores em ralação ao concreto tradicional. Oyarzo e Peuportier (2014) utilizaram a ACV para avaliar a habitação no contexto chileno, levando em consideração os materiais de acabamento das edificações, o conforto térmico e o consumo de energia, constatou-se que a melhora da isolação térmica, juntamente com a mudança de orientação das janelas seu tipo de vidro, diminui as emissões de $\mathrm{CO}_{2} / \mathrm{m}^{2}$ associadas ao uso de energia elétrica, e que as reduções são mais significativas em locais com o clima frio. Ingrao et al. (2018) empregaram a ACV para avaliar a sustentabilidade de edifícios com ênfase na eficiência energética, demonstrando a necessidade de normatização na construção de edifícios residenciais, almejando melhorias do seu desempenho ambiental. Kamali et al., (2019) utilizaram a ACV para comparar a sustentabilidade de uma construção convencional e uma modular, eles concluíram que edifícios modulares apresentam menores impactos ambientais em relação ao convencional. Nematchoua et al., (2019) empregaram a ACV para edificações residenciais em um clima temperado do norte europeu, levando em consideração a relação entre os materiais de acabamento, a eficiência energética e emissões. Os mesmos constataram que os impactos ambientais de edifícios antigos são significativamente maiores, sendo que na fase de uso ocorre o maior consumo de energia do ciclo de vida (de 81,0 a 94,3\%), bem como a maior contribuição para gases relacionados ao efeito estufa.

No contexto brasileiro, Stafford et al. (2016) estudaram a ACV do cimento Portland produzido no país e constatou que a etapa de transporte tem papel relevante em termos de emissões, seguidos da produção de combustíveis fósseis e do clínquer, esse resultado se deve a utilização de transporte por rodovias, que aumenta consideravelmente o consumo de combustíveis fósseis em relação ao transporte por ferrovias. Medeiros, Durante e Callejas (2018) fizeram um estudo comparativo da ACV para diversos sistemas construtivos e constataram que os sistemas de superestrutura, cobertura e vedações foram os mais prejudiciais ao meio ambiente. Azevedo, Geraldi e Ghisi (2020) realizaram o estudo de ACV para diferentes conjuntos de parede e cobertura em habitações de interesse social em Florianópolis, verificaram que o uso de paredes de tijolo de adobe e cobertura com forro de madeira tendem a ter menores impactos ambientais.

Segundo Ortiz et al., (2009), a ACV teve mais aplicações em sistemas e componentes do que em edificações como um todo. No contexto nacional, Medeiros, Durante e Callejas (2018) verificaram a mesma tendencia e constataram que a inexistência de um inventário com dados nacional, juntamente com as incertezas inerentes de aplicação de dados de ACV com base de dados internacionais agrava o problema, pois no âmbito da construção civil nacional, alguns materiais amplamente difundidos no país não são empregados com frequência em países de origem do banco de dados, por questões culturais, climáticas e econômicas. Outro fator que dificulta o estudo com dados nacionais são questões relacionadas aos segredos industriais, isto é, as fábricas muitas vezes se negam a fornecer informações relacionadas ao ciclo de vida.

Dessa forma, o objetivo principal deste trabalho é quantificar os impactos ambientais potenciais negativos dos insumos mais relevantes usados na construção de edificações residenciais por $\mathrm{m}^{2}$ de área construída. O conhecimento dos impactos ambientais negativos provocados ao longo da cadeia produtiva da construção civil habitacional é uma iniciativa importante para diagnosticar onde e como estão ocorrendo os maiores consumos. Essa informação poderá ser utilizada como parâmetro ecológico a ser considerado na elaboração de projetos arquitetônicos de construções sustentáveis, contribuindo para a escolha de tipos de acabamentos, além de outras concepções arquitetônicas. Possibilitará também que os fabricantes revejam seus processos de fabricação, voltados à sustentabilidade com a substituição de alguns materiais de construção por outros com menor potencial de impactos ambientais adversos. 


\section{Metodologia}

\subsection{Método}

$\mathrm{O}$ procedimento metodológico foi realizado em três etapas. Na primeira etapa foram escolhidos três projetos habitacionais que são representativos dos padrões construtivos predominantes no Brasil. Na segunda etapa, tomando como base os projetos referências, foi calculado o quantitativo total de insumos para a execução da edificação, em seguida, dividiu esse quantitativo pelo número de habitações e pelas suas respectivas áreas, determinando assim, o quantitativo por $\mathrm{m}^{2}$ de área construída. Na terceira etapa foi determinada a ACV dos insumos mais relevantes.

\subsection{Escolha dos projetos habitacionais de referência}

Os projetos selecionados para pesquisa visam representar as habitações mais comuns no país, em termos arquitetônicos, padrões de acabamento, materiais de construção e técnicas construtivas. Nesse contexto, os projetos utilizados em programas governamentais habitacionais, sobretudo os empreendimentos financiados pela Caixa Econômica Federal, como o PMCMV, renomeado para Casa Verde e Amarelo, são representativos, uma vez que são utilizados como referência para estimar o custo por $\mathrm{m}^{2}$ de área a ser construída, bem como na avaliação de imóveis existentes. Além disso, entre 2009 e 2020 foram entregues mais de 5,1 milhões de moradias (Brasil, 2020).

As especificações construtivas dos projetos utilizados como referência estão apresentados no Quadro 1 e suas características físicas na Tabela 1.

Quadro 1 - Características construtivas dos projetos de referência.

\begin{tabular}{|l|l|}
\hline $\begin{array}{l}\text { Projetos de } \\
\text { referência }\end{array}$ & Descrição \\
\hline Projeto 1 & $\begin{array}{l}\text { Edificação residencial unifamiliar (casa) térrea com sala, dois quartos, banheiro, cozinha e tanque externo sem cobertura. } \\
\text { Planta acessível para PCR (Pessoa em Cadeira de Rodas). }\end{array}$ \\
\hline Projeto 2 & $\begin{array}{l}\text { Edificação residencial multifamiliar (bloco) de quatro pavimentos-tipo sem elevador. Cada pavimento com quatro } \\
\text { apartamentos, totalizando 16 unidades habitacionais. Cada uma composta por sala, 2 quartos, banheiro, cozinha e área de } \\
\text { serviço. Inclui abrigo de medidores de gás e 1 vaga de garagem descoberta por unidade (piso externo). Todas as unidades } \\
\text { possuem plantas acessíveis para PCR (Pessoa em Cadeira de Rodas). }\end{array}$ \\
\hline Projeto 3 & $\begin{array}{l}\text { Edificação residencial multifamiliar (bloco) de 18 pavimentos (16 pavimentos-tipo, 1 piloti térreo e um subsolo de } \\
\text { garagem). Com 2 elevadores, 128 vagas de garagem e depósito de lixo no subsolo; hall de entrada, salão de festas, } 2 \\
\text { lavabos, copa, banheiro de serviço e depósito nos pilotis; guarita e abrigo de medidores de gás. Cada pavimento-tipo com 4 } \\
\text { apartamentos, totalizando 64 unidades habitacionais, cada uma composta por sala, varanda, 1 suíte, 2 quartos, circulação, 3 } \\
\text { banheiros, cozinha e área de serviço. }\end{array}$ \\
\hline
\end{tabular}

Fonte: Caixa Econômica Federal (2017).

Tabela 1 - Características físicas dos projetos de referências.

\begin{tabular}{l|r|r|r}
\hline Características físicas & Projeto 1 & Projeto 2 & Projeto 3 \\
\hline Quantidade de pavimento tipo & 1 & 4 & 16 \\
\hline Quantidade total de pavimentos & 1 & 4 & 18 \\
\hline Quantidade de apartamentos por pavimento & 1 & 4 & 4 \\
\hline Quantidade total de apartamentos & 1 & 16 & 64 \\
\hline Área do apartamento tipo & 43,61 & 44,49 & 78,95 \\
\hline Área total dos apartamentos & - & 714,14 & $5.052,91$ \\
\hline Áreas comuns (garagens, pilotis, escadas) & - & 974,83 & $4.879,52$ \\
\hline Área de circulação e hall & - & 81,27 & 679,60 \\
\hline Área total & 43,61 & $1.770,24$ & $10.612,03$ \\
\hline
\end{tabular}

Fonte: Caixa Econômica Federal (2017). 
Cada projeto tem seu sistema construtivo específico, sendo que o projeto 1 é uma casa térrea com alvenaria autoportante, o projeto 2 é um prédio com quatro pavimentos em alvenaria estrutural, já o projeto 3 é um edifício em concreto armado com 18 pavimentos. Os projetos de arquitetura utilizados como referência estão apresentados nas Figuras 1 a 3.

Figura 1 - Planta baixa e fachada em 3D do projeto de referência 1.

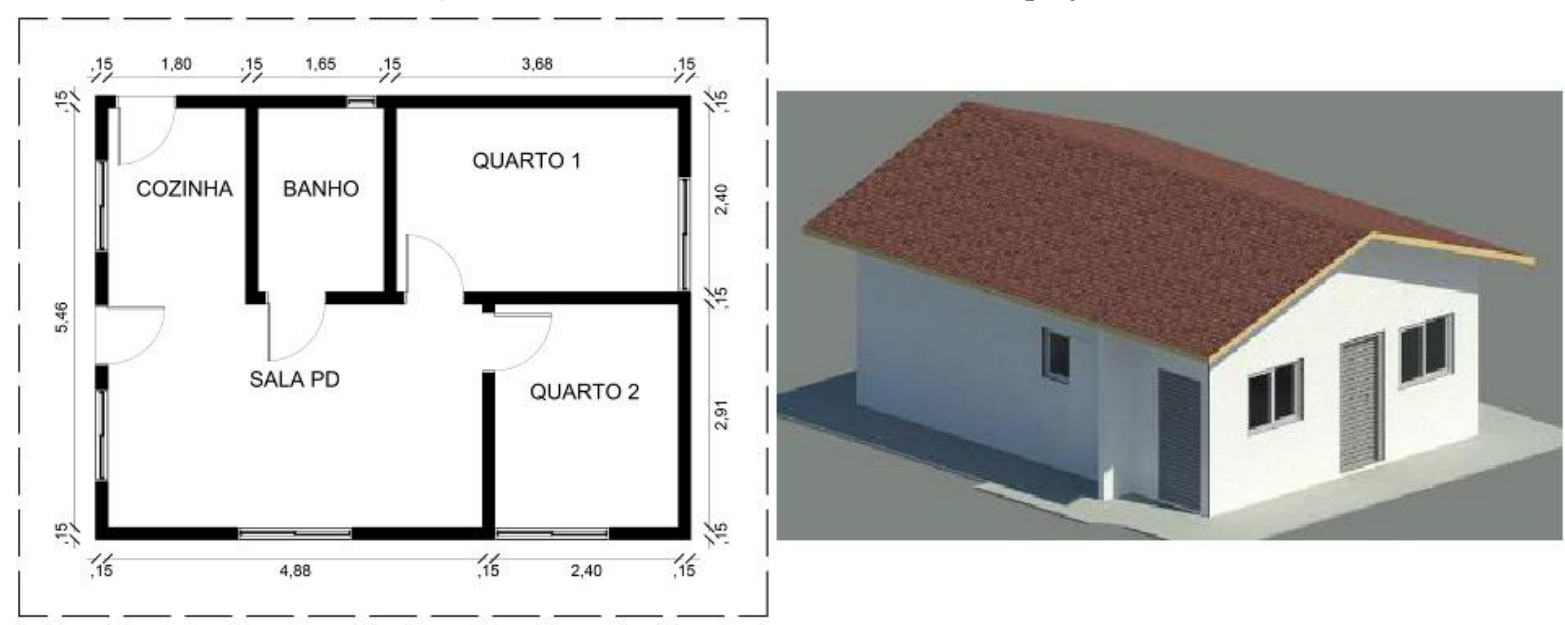

Fonte: Caixa Econômica Federal (2017).

Figura 2 - Planta baixa e fachada em 3D do projeto de referência 2.
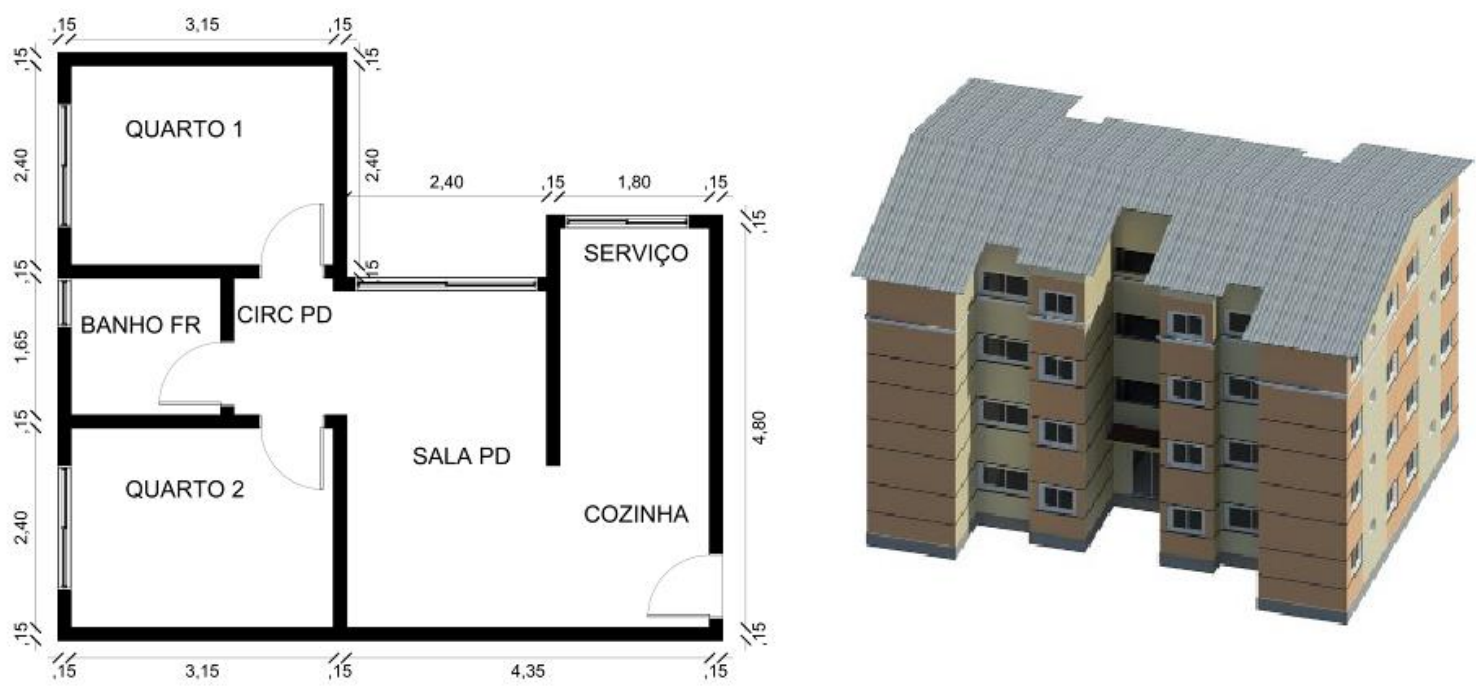

Fonte: Caixa Econômica Federal (2017). 
Figura 3 - Planta baixa e fachada em 3D do projeto de referência 3.

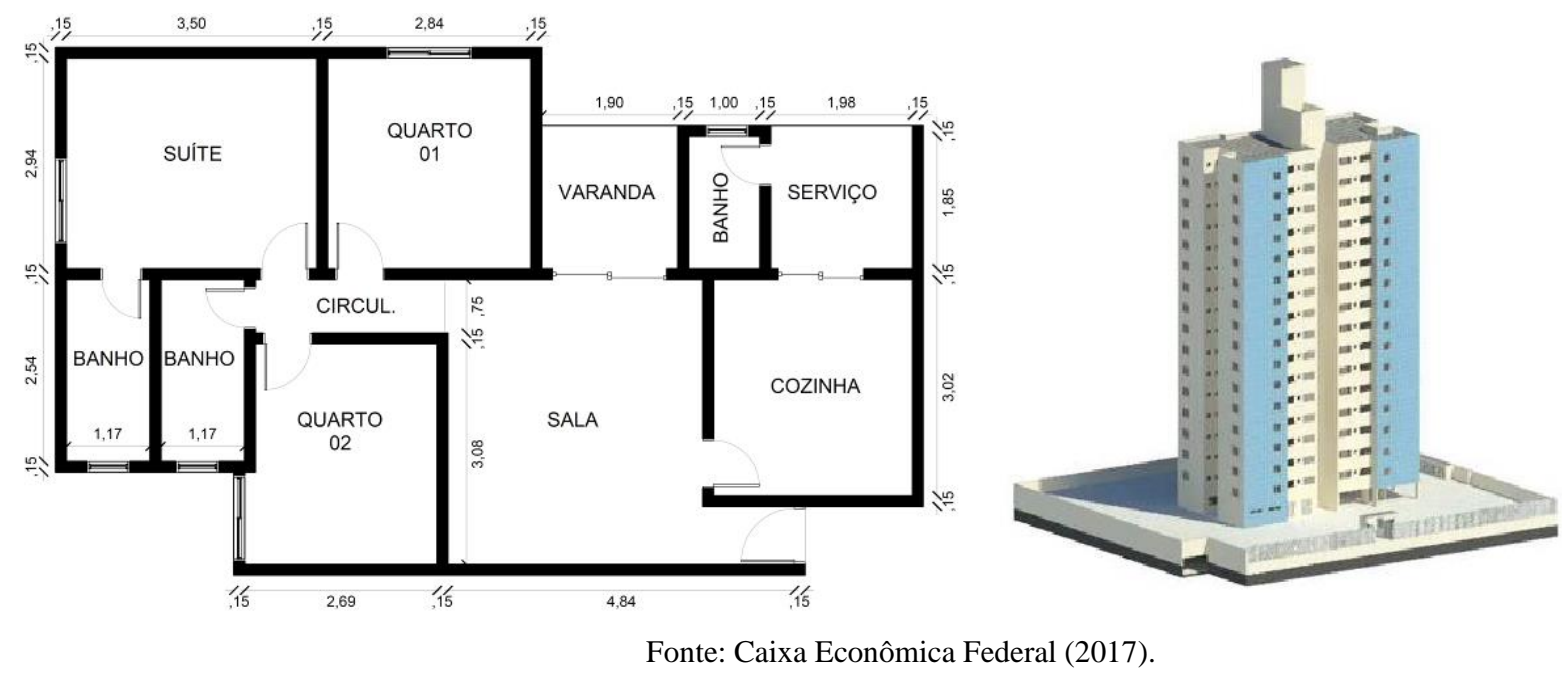

\subsection{Levantamento dos insumos}

O levantamento dos quantitativos de insumos seguiu a metodologia preconizada pelo Sistema Nacional de Pesquisa de Custos e Índices da Construção Civil - SINAPI (Caixa Econômica Federal, 2020). Esse sistema é administrado pela Caixa Econômica Federal, que periodicamente atualiza todas as informações técnicas como catálogo de especificação de insumos, custos da construção civil habitacional por $\mathrm{m}^{2}$ de construção, levando em consideração os padrões construtivos (área, tipo de acabamento e quantidade de pavimentos), além dos custos de insumos e serviços para as 27 capitais brasileiras com suas respectivas composições de custos.

O SINAPI é utilizado como sistema padrão de referência de preços em obras públicas, conforme a Lei $\mathrm{n}^{\circ} 11.514$, de 13 de agosto de 2007, em seu artigo Art. 115 estabelece que:

Art. 115. Os custos unitários de materiais e serviços de obras executadas com recursos dos orçamentos da União não poderão ser superiores à mediana daqueles constantes do Sistema Nacional de Pesquisa de Custos e Índices da Construção Civil - SINAPI, mantido pela Caixa Econômica Federal, que deverá disponibilizar tais informações na internet. (Brasil 2007

As obras que empregam recursos da União têm seus custos levantados com base no sistema SINAPI e nas suas composições de custos. O sistema é auditado constantemente pelo Tribunal de Contas da União (TCU) e pela Controladoria Geral da União (CGU), por isso está em constante revisão e aperfeiçoamento, tal fato garante representatividade do sistema SINAPI (Caixa Econômica Federal, 2021). Nessa metodologia, os custos básicos unitários (CUB), são levantados através de composições de custos, estas consistem no conjunto de insumos e seus respectivos coeficientes de produtividade e custos unitários necessários para executar uma unidade de serviço.

Os insumos foram levantados, conforme metodologia preconizada pela Caixa Econômica Federal (2020), cujo fluxograma está apresentado na Figura 4. 
Figura 4 - Fluxograma das etapas para obtenção dos quantitativos totais de insumos.

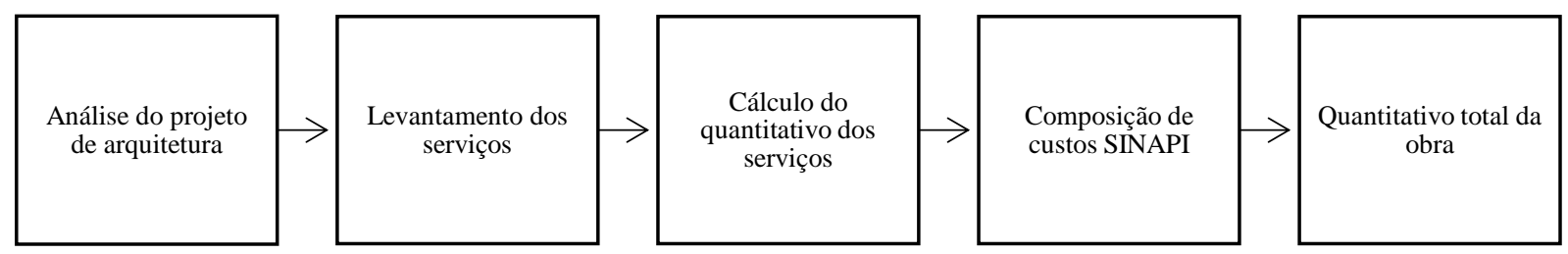

Fonte: Autores.

O levantamento de dados iniciou-se com a análise do projeto de arquitetura e projetos complementares, em seguida foi feito o levantamento dos serviços necessários para concluir a obra com seus respectivos quantitativos- De posse destes dados, os insumos são obtidos a partir das composições analíticas do SINAPI, da Caixa Econômica Federal (2021), pelo produto do quantitativo de serviços e os seus respectivos coeficientes de produtividade.

\subsection{Avaliação do Ciclo de Vida}

\subsubsection{Software de avaliação do ciclo de vida.}

Tendo em vista a grande quantidade de insumos e sua complexidade para a fabricação, que muitas vezes envolve segredos industriais, nos quais as fábricas não estão dispostas a disponibilizar para pesquisa, tais fatores torna difícil realizar a ACV individualizada para todos os insumos da obra. Para a realização deste trabalho foram escolhidos os insumos que são utilizados em grandes quantidades, bem como os mais representativos da Curva ABC.

A curva $\mathrm{ABC}$ é um método que se baseia no Princípio de Pareto, economista italiano do século XIX que observou que havia uma distribuição desigual da riqueza na Itália, em que $80 \%$ dessa riqueza estava nas mãos de apenas $20 \%$ da população. Também chamado de Princípio 80/20, sintetiza a ocorrência de um determinado fator frente ao seu universo de amostras (Mattos, 2006). Esses insumos contemplam a parte de estruturas, alvenarias, revestimentos, esquadrias, fiação das instalações elétricas e pintura.

Para elaboração deste trabalho foi escolhido o software OpenLCA 1.10, por possuir código aberto para ACV, estando disponível gratuitamente, sendo este bastante utilizado em meio acadêmico. Além disso, os resultados podem ser exportados para formato compatível com as planilhas MS-Excel ou OpenOffice.

Na Figura 5 apresenta-se o fluxograma dos elementos e fluxos que compõem o software de ACV OpenLCA, e como estes se relacionam entre si. A descrição de cada elemento e fluxo estão apresentados no Quadro 2. 
Figura 5 - Estrutura dos elementos do banco de dados e fluxo de informações do OpenLCA.

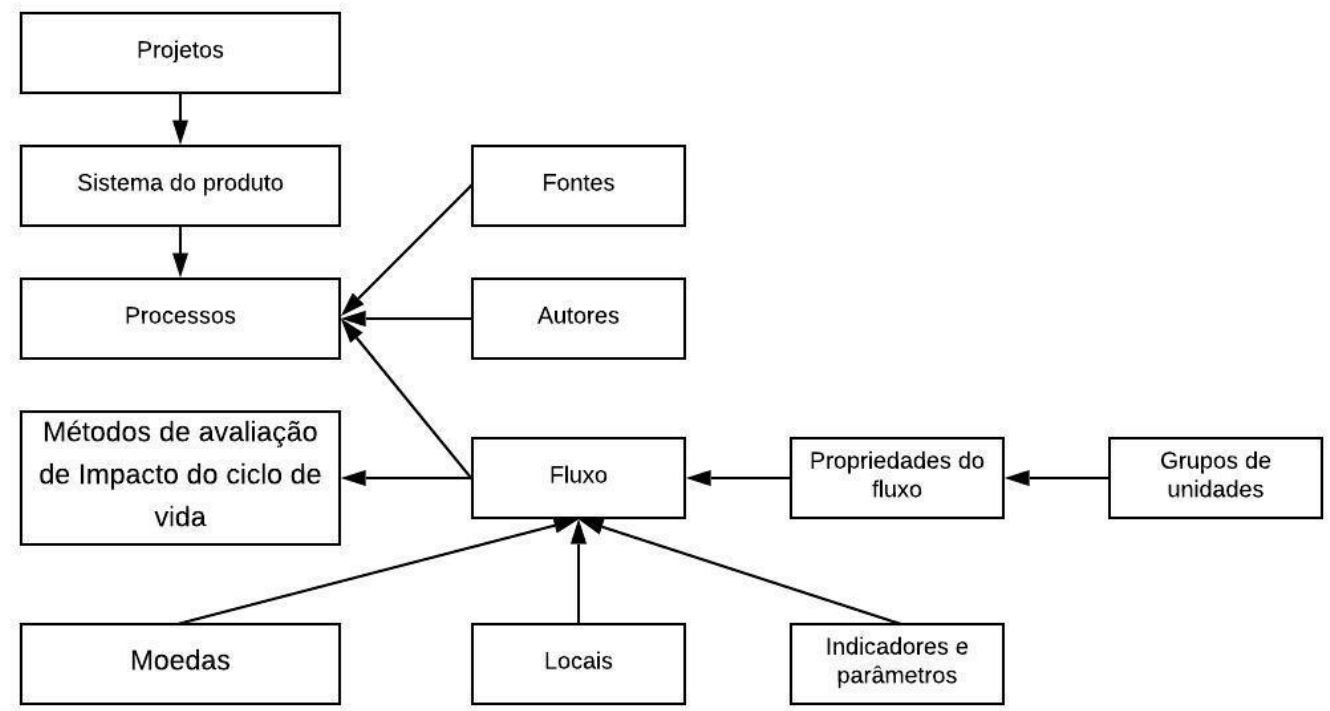

Fonte: Adaptado e traduzido de Ciroth et al. (2019).

Quadro 2 - Principais comandos de navegação do OpenLCA.

\begin{tabular}{|l|l|}
\hline Elemento & Resumo \\
\hline Autores & Pessoas que forneceram dados ou modificaram modelos. \\
\hline Moedas & Valor financeiro atribuído ao fluxo e a execução do ciclo de vida. \\
\hline Locais & Dado utilizado para a regionalização da ACV. \\
\hline Fontes & Literatura referenciada. \\
\hline Grupos de unidades & Unidades utilizadas na ACV. \\
\hline Propriedades do fluxo & Características físicas dos fluxos (por exemplo, comprimento, massa, etc.). \\
\hline Fluxos & $\begin{array}{l}\text { No Software este é o comendo de navegação (Flows), que é definido como produto, um fluxo elementar ou um } \\
\text { fluxo de resíduos. Além disso, uma propriedade de fluxo de referência deve ser definida, como por exemplo, } \\
\text { suas unidades. }\end{array}$ \\
\hline Processos & $\begin{array}{l}\text { No Software este é o comendo de navegação (Process). Um processo é uma atividade que transforma entrada } \\
\text { (s) em uma saída (s), para a produção ou modificação de produtos e materiais, tanto a entradas ou as saídas são } \\
\text { informadas ao software através de fluxos. }\end{array}$ \\
\hline Métodos de impacto & $\begin{array}{l}\text { Métodos de avaliação de impacto importados para o OpenLCA, através deste é possível incluir ou excluir } \\
\text { categorias de impactos dos resultados. Entretanto, deve-se verificar se há compatibilidade entre os métodos de } \\
\text { impactos e o banco de dados. }\end{array}$ \\
\hline Sistemas do produto & $\begin{array}{l}\text { No Software este é o comendo de navegação (Product systems). Como na ISO 14040, o modelo de ciclo de } \\
\text { vida de um produto é chamado de sistema do produto. Que é criado com base no (s) processo (s). Neste } \\
\text { comando serão feitos os cálculos dos resultados e o impacto do inventário de avaliação do OpenLCA. }\end{array}$ \\
\hline Projetos & $\begin{array}{l}\text { No Software este é o comendo de navegação (Projects). Com este comando podem ser criados cenários para } \\
\text { comparar variantes do sistema do produto. }\end{array}$ \\
\hline $\begin{array}{l}\text { Indicators and } \\
\text { parameters }\end{array}$ & $\begin{array}{l}\text { Comando de navegação (Indicators and parameters). Que são indicadores sociais, parâmetros globais, } \\
\text { sistemas de qualidade de dados. }\end{array}$ \\
\hline
\end{tabular}

Fonte: Adaptado e traduzido de (CIROTH et al., 2019)

\subsubsection{Inventário da Avaliação do Ciclo de Vida}

O banco de dados utilizado para realizar o inventário do ciclo de vida dessa pesquisa foi o Environmental Footprints. Este realiza a ACV a partir das Pegadas Ambientais dos produtos e faz uma avaliação quantitativa de impactos ambientais, tendo sido desenvolvido a partir da iniciativa da Comissão Europeia para o mercado único de produtos verdes (Greendelta, 2020). É disponibilizado gratuitamente, mediante um cadastro, e contém um conjunto de dados de inventários de ciclo de vida, que abrange boa parte dos materiais de construção. No Quadro 3 são apresentadas as categorias de impactos consideradas nesse banco de dados e avaliadas nesta pesquisa, juntamente com seus indicadores e unidades. 
Quadro 3 - Categoria de impactos, indicadores e unidades utilizadas na ACV.

\begin{tabular}{|c|c|c|}
\hline Categoria de impacto & Indicador & Unidades \\
\hline Acidificação & Excedente acumulado & $\mathrm{mol} \mathrm{H}^{+} \mathrm{eq}$ \\
\hline Mudanças climáticas & $\begin{array}{l}\text { Força radioativa com potencial de } \\
\text { aquecimento global }\end{array}$ & $\mathrm{kg} \mathrm{CO} 2 \mathrm{eq}$ \\
\hline Mudança climática - Biogênica & $\begin{array}{l}\text { Força radioativa com potencial de } \\
\text { aquecimento global }\end{array}$ & $\mathrm{kg} \mathrm{CO} 2 \mathrm{eq}$ \\
\hline $\begin{array}{l}\text { Mudança climática - combustível } \\
\text { fóssil }\end{array}$ & $\begin{array}{l}\text { Força radioativa com potencial de } \\
\text { aquecimento global }\end{array}$ & $\mathrm{kg} \mathrm{CO}_{2} \mathrm{eq}$ \\
\hline $\begin{array}{l}\text { Mudança climática - uso do solo e } \\
\text { mudança no uso do solo }\end{array}$ & $\begin{array}{l}\text { Força radioativa com potencial de } \\
\text { aquecimento global }\end{array}$ & $\mathrm{kg} \mathrm{CO}_{2} \mathrm{eq}$ \\
\hline Ecotoxicidade em água doce & $\begin{array}{l}\text { Unidade Tóxica Comparativa para } \\
\text { Ecossistemas (CTUe) }\end{array}$ & CTUe \\
\hline Eutrofização marinha & $\begin{array}{l}\text { Fração de nutrientes despejados no } \\
\text { mar }\end{array}$ & $\mathrm{kg} \mathrm{N} \mathrm{eq}$ \\
\hline Eutrofização em água doce & $\begin{array}{l}\text { Fração de nutrientes despejados em } \\
\text { água doce }\end{array}$ & kg P eq \\
\hline Eutrofização terrestre & Excedente acumulado & mol $\mathrm{N}$ eq \\
\hline Toxicidade humana, câncer & $\begin{array}{l}\text { Unidade Tóxica Comparativa para } \\
\text { Humanos (CTUh) }\end{array}$ & CTUh \\
\hline Toxicidade humana, não câncer & $\begin{array}{l}\text { Unidade Tóxica Comparativa para } \\
\text { Humanos }\end{array}$ & CTUh \\
\hline Radiação ionizante, saúde humana & $\begin{array}{l}\text { Efeitos de exposição humana em } \\
\text { relação a radiação do U }{ }^{235}\end{array}$ & $\mathrm{kBq} \mathrm{\textrm {U } ^ { 2 3 5 }}$ \\
\hline Uso do solo & $\begin{array}{l}\text { Índice de qualidade do solo } \\
\text { (Produção biótica, resistência à } \\
\text { erosão, filtragem mecânica e reposição } \\
\text { de águas subterrâneas) }\end{array}$ & $\begin{array}{l}\text { Item(s) - Adimensional, } \\
\text { índice agregado de kg (produção } \\
\text { biótica) / } \\
(\mathrm{m} 2 * \text { a) } \mathrm{kg} \text { solo / } \\
(\mathrm{m} 2 * \text { a) } \mathrm{m} 3 \text { água / (m2 * a) } \mathrm{m} 3 \mathrm{~g} . \\
\text { água / }(\mathrm{m} 2 * \mathrm{a})\end{array}$ \\
\hline Depleção de ozônio & Destruição potencial de ozônio & kg CFC-11 eq \\
\hline Material particulado & $\begin{array}{l}\text { Efeitos na saúde humana associados à } \\
\text { exposição a de material particulado } \\
\text { com } 2.5 \mu \mathrm{m}\end{array}$ & PM2.5 \\
\hline $\begin{array}{l}\text { Formação fotoquímica de ozônio - } \\
\text { saúde humana }\end{array}$ & $\begin{array}{l}\text { Diminuição da concentração de } \\
\text { ozônio troposférico }\end{array}$ & kg COVNM eq \\
\hline Uso de recursos, fósseis & $\begin{array}{l}\text { Esgotamento de recursos abióticos - } \\
\text { combustíveis fósseis }\end{array}$ & MJ \\
\hline Uso de recursos, minerais e metais & Esgotamento de recursos abióticos & $\mathrm{kg} \mathrm{Sb}$ eq \\
\hline Uso de água & $\begin{array}{l}\text { Privação potencial de consumo de } \\
\text { água. }\end{array}$ & $\begin{array}{l}\mathrm{m}^{3} \text { de } \mathrm{H}_{2} \mathrm{O} \text { (em relação ao consumo } \\
\text { médio mundial) }\end{array}$ \\
\hline
\end{tabular}

Fonte: Traduzido e adaptado de Fazio et al. (2018).

\section{Resultados e Discussão}

\subsection{Levantamento dos insumos}

Para esta pesquisa foram levantados todos os insumos dos projetos habitacionais, e estes foram divididos e categorizados da seguinte maneira:

1- Mão de obra e encargos trabalhistas: baseados nas horas/homens necessárias de cada profissional para concluir a obra, bem como os encargos trabalhistas exigidos pela legislação;

2- Insumos relevantes: insumos mais utilizados em obras em geral, bem como os mais representativos na curva ABC, contemplando estrutura, paredes, acabamentos e revestimentos da edificação, pintura e portas;

3- Equipamentos, ferramentas e EPI's: Estes itens contemplam aquisição ou aluguel de equipamentos, ferramentas e equipamentos de proteção individual. Como a maioria destes insumos podem ser reutilizados em outras obras, estes itens não foram considerados nesta pesquisa;

4- Demais insumos: são os demais insumos que não serão analisados na pesquisa. 
A lista completa destes insumos está apresentada na Tabela 2, juntamente com os seus custos e o percentual em relação ao custo total da obra.

A representatividade dos insumos em relação aos custos das obras nos projetos de referência está ilustrada na Figura 6.

Tabela 2 - Insumos relevantes com os respectivos custos e o percentual em relação ao custo total da obra.

\begin{tabular}{|c|c|c|c|c|c|c|c|}
\hline \multirow[b]{2}{*}{ Insumo } & \multirow[b]{2}{*}{ Legenda } & \multicolumn{2}{|l|}{ Projeto 1} & \multicolumn{2}{|l|}{ Projeto 2} & \multicolumn{2}{|l|}{ Projeto 3} \\
\hline & & Custo (R\$) & $\%$ & Custo (R\$) & $\%$ & Custo (R\$) & $\%$ \\
\hline Cimento Portland & CIM & \multicolumn{2}{|l|}{$2.356,98$} & $42.258,29$ & 5,6 & $452.414,81$ & 7,3 \\
\hline Blocos de concreto & BLC & - & 0,0 & $55.818,85$ & 7,4 & \multirow[b]{2}{*}{$51.765,08$} & 0,0 \\
\hline $\mathrm{Cal}$ & CAL & 471,33 & 0,9 & $4.725,66$ & 0,6 & & 0,8 \\
\hline Gesso & GES & - & 0,0 & $4.451,58$ & 0,6 & $1.150,75$ & 0,0 \\
\hline Laje & $\mathrm{LJ}$ & $1.173,74$ & 2,3 & - & 0,0 & \multirow{2}{*}{$\begin{array}{r}- \\
192.679,89\end{array}$} & 0,0 \\
\hline Areia & $\mathrm{AR}$ & $1.197,76$ & 2,3 & $18.124,37$ & 2,4 & & 3,1 \\
\hline Brita & $\mathrm{BR}$ & 365,04 & 0,7 & $6.550,44$ & 0,9 & $60.100,84$ & 1,0 \\
\hline Aço CA-50 & CA50 & $1.839,70$ & 3,5 & $37.003,94$ & 4,9 & $49.872,22$ & 0,8 \\
\hline Aço CA-60 & CA60 & 103,09 & 0,2 & $37.928,28$ & 5,1 & $35.539,86$ & 0,6 \\
\hline Madeira & MD & $5.571,55$ & 10,7 & $22.882,27$ & 3,0 & $145.820,12$ & 2,4 \\
\hline Chapa compensada & $\mathrm{CP}$ & - & 0,0 & $7.846,92$ & 1,0 & $143.074,30$ & 2,3 \\
\hline Revestimento cerâmico & $\mathrm{RC}$ & 975,83 & 1,9 & $20.694,50$ & 2,8 & $383.591,90$ & 6,2 \\
\hline Peças cerâmicas (tijolo, telhas) & PC & $2.918,10$ & 5,6 & 52,04 & 0,0 & $102.180,37$ & 1,6 \\
\hline Porta de correr em alumínio e vidro & PAV & - & 0,0 & $1.421,97$ & 0,2 & $152.568,66$ & 2,5 \\
\hline Janela de correr em alumínio e vidro & JAV & - & 0,0 & $42.833,57$ & 5,7 & $128.442,47$ & 2,1 \\
\hline $\begin{array}{l}\text { Porta em perfis de alumínio tipo } \\
\text { veneziana }\end{array}$ & PAVV & $1.446,00$ & 2,8 & $3.976,51$ & 0,5 & $1.355,63$ & 0,0 \\
\hline $\begin{array}{l}\text { Porta prensada, chapa em HDF, núcleo } \\
\text { sarrafeado }\end{array}$ & PM & 566,28 & 1,1 & $12.080,64$ & 1,6 & $96.658,46$ & 1,6 \\
\hline Cabos elétricos de cobre & $\mathrm{CAB}$ & 559,15 & 1,1 & $11.444,10$ & 1,5 & $178.198,91$ & 2,9 \\
\hline Tinta para paredes & TINT & 923,86 & 1,8 & $11.057,20$ & 1,5 & $79.450,11$ & 1,3 \\
\hline & Total & $20.468,41$ & 39,3 & $341.151,14$ & 45,5 & $2.254 .864,39$ & $\overline{36,4}$ \\
\hline
\end{tabular}

Fonte: Autores.

Figura 6 - Custos relativos das categorias de insumos.

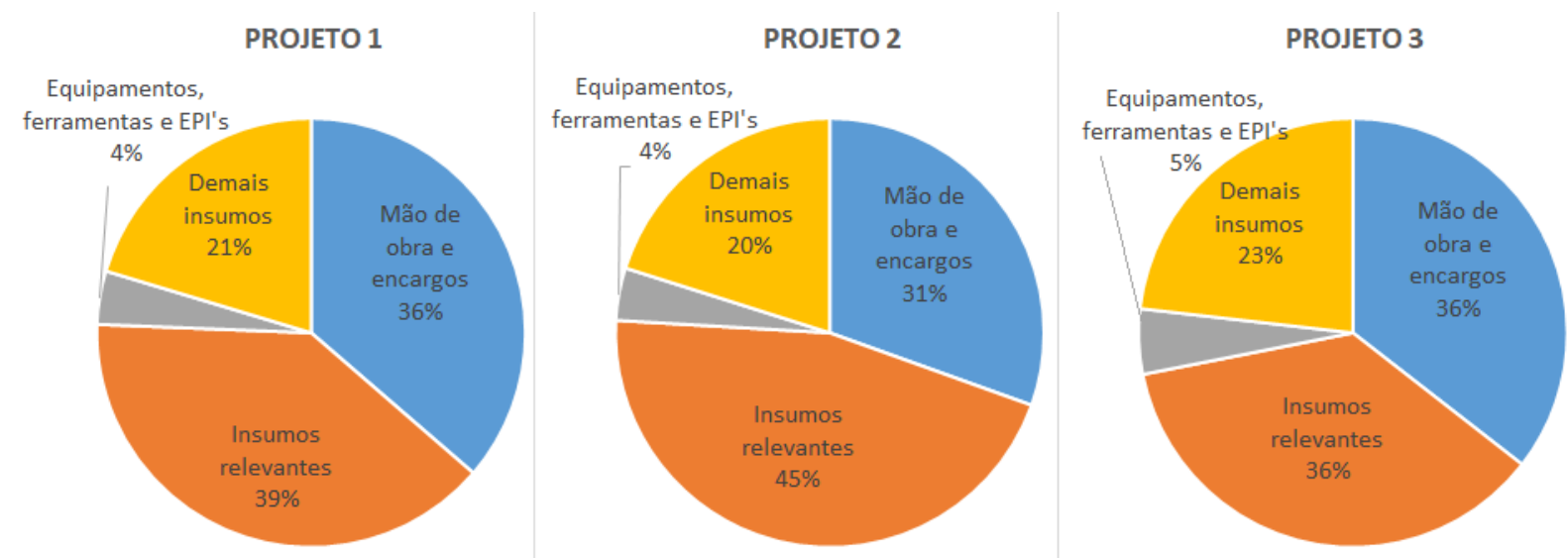

Fonte: Autores.

\subsection{Avaliação do ciclo de vida dos projetos de referência}

A ACV por $\mathrm{m}^{2}$ de área construída, referente aos insumos de maior relevância dos projetos de referência está apresentada na Tabela 3. 
Tabela 3 - Valores dos impactos negativos da ACV por $\mathrm{m}^{2}$ de área construída dos projetos de referência.

\begin{tabular}{|c|c|c|c|c|}
\hline Categoria de impacto negativo & Unidade & Projeto 1 & Projeto 2 & Projeto 3 \\
\hline Acidificação & mol H+ eq & $9,29 \mathrm{E}-01$ & $1,24 \mathrm{E}+00$ & $1,30 \mathrm{E}+00$ \\
\hline Mudanças climáticas & $\mathrm{kg} \mathrm{CO}_{2}$ eq & $3,24 \mathrm{E}+02$ & $3,85 \mathrm{E}+02$ & $4,05 \mathrm{E}+02$ \\
\hline Mudança climática - Biogênica & $\mathrm{kg} \mathrm{CO} 2 \mathrm{eq}$ & $4,61 \mathrm{E}+00$ & $6,23 \mathrm{E}+00$ & $7,81 \mathrm{E}+00$ \\
\hline Mudança climática - combustível fóssil & $\mathrm{kg} \mathrm{CO} 2 \mathrm{eq}$ & $3,19 \mathrm{E}+02$ & $3,79 \mathrm{E}+02$ & $3,97 \mathrm{E}+02$ \\
\hline Mudança climática - uso do solo e mudança no uso do solo & $\mathrm{kg} \mathrm{CO}_{2} \mathrm{eq}$ & $1,61 \mathrm{E}-01$ & $1,55 \mathrm{E}-01$ & $1,75 \mathrm{E}-01$ \\
\hline Ecotoxicidade em água doce & CTUe & $9,15 \mathrm{E}+02$ & $1,29 \mathrm{E}+03$ & $1,63 \mathrm{E}+03$ \\
\hline Eutrofização marinha & $\mathrm{kg} \mathrm{N} \mathrm{eq}$ & $3,29 \mathrm{E}-01$ & $4,24 \mathrm{E}-01$ & $4,78 \mathrm{E}-01$ \\
\hline Eutrofização em água doce & $\mathrm{kg} P$ eq & $9,78 \mathrm{E}-03$ & $1,33 \mathrm{E}-02$ & $1,79 \mathrm{E}-02$ \\
\hline Eutrofização terrestre & mol $\mathrm{N}$ eq & $2,79 \mathrm{E}+00$ & $3,50 \mathrm{E}+00$ & $3,80 \mathrm{E}+00$ \\
\hline Toxicidade humana, câncer & CTUh & 3,04E-06 & 4,19E-06 & $5,29 \mathrm{E}-06$ \\
\hline Toxicidade humana, não câncer & CTUh & $6,02 \mathrm{E}-05$ & $8,36 \mathrm{E}-05$ & $1,02 \mathrm{E}-04$ \\
\hline Radiação ionizante, saúde humana & $\mathrm{kBq} \mathrm{U} 235$ & $1,50 \mathrm{E}+01$ & $1,75 \mathrm{E}+01$ & $2,10 \mathrm{E}+01$ \\
\hline Uso do solo & $\operatorname{Item}(s)$ & $2,53 \mathrm{E}+04$ & $1,65 \mathrm{E}+04$ & $2,25 \mathrm{E}+04$ \\
\hline Depleção de ozônio & kg CFC-11eq & $1,53 \mathrm{E}-06$ & $2,13 \mathrm{E}-06$ & $2,75 \mathrm{E}-06$ \\
\hline Material particulado & kg PM2.5 & $1,42 \mathrm{E}-03$ & $1,79 \mathrm{E}-03$ & 1,99E-03 \\
\hline Formação fotoquímica de ozônio - saúde humana & kg COVNM eq & $6,69 \mathrm{E}-01$ & $8,30 \mathrm{E}-01$ & $8,60 \mathrm{E}-01$ \\
\hline Uso de recursos, fósseis & MJ & $2,57 \mathrm{E}+03$ & $3,17 \mathrm{E}+03$ & $3,31 \mathrm{E}+03$ \\
\hline Uso de recursos, minerais e metais & $\mathrm{kg} \mathrm{Sb}$ eq & $2,48 \mathrm{E}-03$ & $3,86 \mathrm{E}-03$ & 3,38E-03 \\
\hline Uso de água & $\mathrm{m}^{3}$ & $5,49 \mathrm{E}+01$ & $7,52 \mathrm{E}+01$ & $8,82 \mathrm{E}+01$ \\
\hline
\end{tabular}

Fonte: Autores.

Analisando ainda os dados da Tabela 3, em termos absolutos, os maiores impactos ambientais negativos são verificados nas categorias de uso do solo, uso de recursos fósseis, ecotoxicidade em água doce, mudanças climáticas e uso de água, com exceção do uso do solo onde os impactos estão relacionados ao uso de madeira e o desmatamento, nesta categoria, verifica-se que o projeto 3,com 18 pavimentos gera menos impactos ambientais negativos por $\mathrm{m}^{2}$ de área construída, comparando-se ao projeto 1 , com menor número de pavimentos. Isso ocorre porque o projeto 1 tem o maior consumo de madeira por $\mathrm{m}^{2}$, devido a estrutura de madeira para as telhas cerâmicas. Os demais impactos estão associados ao uso de fornos nos processos de fabricação e aos combustíveis fosseis.

Ainda com base nos dados expostos na Tabela 3, pode-se observar que, na maioria das categorias de impactos ambientais negativos estudadas, o acréscimo do número de pavimentos ocasiona o aumento das emissões nocivas ao meio ambiente e uso de recursos naturais por $\mathrm{m}^{2}$ de área construída. Uma vez que, edificações multifamiliares demandam o incremento de áreas comuns, sobretudo para garagens, podendo haver vários pavimentos apenas para esta finalidade. Essa constatação pode ser observada no Projeto 3 que possui 18 pavimentos, sendo dois dedicados a garagem.

Constata-se dessa forma, que o acréscimo do número de pavimentos exige soluções estruturais mais robustas para a edificação resistir às cargas acidentais, ao peso próprio e à ação da força do vento. Tais fatores acarretam a ampliação das seções transversais dos elementos estruturais, tanto para alvenarias estruturais, como para estruturas de concreto armado.

Por outro lado, as edificações térreas ou com poucos pavimentos, necessitarão de mais espaço para abrigar o mesmo número de famílias, sendo que as intervenções no solo a ser utilizado, ocasionará impactos ambientais negativos que dependem das condições iniciais do terreno (cobertura vegetal, topografia, rede de drenagem, tipo de solo) e do seu uso e ocupação. Além disso, a preparação do terreno para novas construções tem o potencial de gerar impactos adversos em outras áreas, porque nesta etapa é comum a construção demandar o movimento de terra com corte e aterro.

Moradias com poucos pavimentos, além de demandar mais áreas de terreno, necessitam de mais obras de acessibilidade urbana e infraestrutura, incluindo serviços suplementares de pavimentação das vias de acesso, construção de redes de energia elétrica de média e baixa tenção, saneamento básico, dentre outras. Em contrapartida, os imóveis com muitos pavimentos exigem 
área menor para abrigar o mesmo número de moradias, reduzindo o alcance das obras de acessibilidade e de infraestrutura urbana. Um exemplo disso é a redução do número de postes da rede elétrica e do comprimento das tubulações de saneamento.

Conforme o exposto, os impactos ambientais negativos não se restringem apenas a área ocupada pela habitação, tão pouco a fabricação e utilização dos insumos empregados nesta. Para avaliar quais tipos de edificações geram menor impacto negativo, deve ser analisado em conjunto os danos ambientais decorrentes da construção, em cada caso particular, referente a obtenção do terreno, das obras de acessibilidade e infraestrutura urbana necessárias para viabilizar o funcionamento do imóvel.

\subsection{Avaliação do ciclo de vida dos insumos utilizados na construção dos projetos de referência}

Esta pesquisa realizou a ACV de 19 insumos utilizados na construção dos três projetos de referência. Foram consideradas 19 categorias de impacto negativos, listadas na Tabela 4.

Constatou-se que mais de 50\% dos impactos negativos estão concentrados em apenas dois insumos, diante disto e da grande quantidade de dados, para tornar a análise mais eficiente, a apresentação dos resultados nesta tabela, destaca os dois insumos mais relevantes em ordem decrescente; é o somatório dos impactos ambientais negativos potenciais causados pelos demais insumos, em termos absolutos e percentuais.

Tabela 4 - Impactos adversos dos insumos por $\mathrm{m}^{2}$ de área construída dos projetos de referência

\begin{tabular}{|c|c|c|c|c|c|c|}
\hline \multirow[b]{2}{*}{ Categoria de impacto } & \multicolumn{2}{|l|}{ Projeto 1} & \multicolumn{2}{|l|}{ Projeto 2} & \multicolumn{2}{|l|}{ Projeto 3} \\
\hline & $\begin{array}{l}\text { Insumos } \\
\text { relevantes }\end{array}$ & $\%$ & $\begin{array}{l}\text { Insumos } \\
\text { relevantes }\end{array}$ & $\%$ & $\begin{array}{l}\text { Insumos } \\
\text { relevantes }\end{array}$ & $\%$ \\
\hline \multirow{3}{*}{ Acidificação (mol H+ eq) } & CIM & 45,1 & CIM & 37,2 & CIM & 53,3 \\
\hline & $\mathrm{RC}$ & 20,8 & $\mathrm{RC}$ & 20,5 & $\mathrm{RC}$ & 30,0 \\
\hline & SDM & 34,1 & SDM & 42,3 & SDM & 16,7 \\
\hline \multirow{3}{*}{ Mudanças climáticas $\left(\mathrm{kg} \mathrm{CO}_{2} \mathrm{eq}\right)$} & CIM & 44,0 & CIM & 40,6 & CIM & 58,2 \\
\hline & CAL & 11,0 & $\mathrm{RC}$ & 12,0 & $\mathrm{RC}$ & 17,5 \\
\hline & SDM & 45,1 & SDM & 47,4 & SDM & 24,3 \\
\hline \multirow{3}{*}{$\begin{array}{l}\text { Mudança climática - Biogênica (kg } \\
\mathrm{CO}_{2} \text { eq) }\end{array}$} & CIM & 57,7 & CIM & 46,9 & CIM & 56,4 \\
\hline & $\mathrm{RC}$ & 30,7 & $\mathrm{RC}$ & 29,9 & $\mathrm{RC}$ & 36,6 \\
\hline & SDM & 11,6 & SDM & 23,2 & SDM & 7,0 \\
\hline \multirow{3}{*}{$\begin{array}{l}\text { Mudança climática - combustível } \\
\text { fóssil (kg CO} 2 \text { eq) }\end{array}$} & CIM & 43,8 & CIM & 40,5 & CIM & 58,2 \\
\hline & CAL & 11,1 & $\mathrm{RC}$ & 11,7 & $\mathrm{RC}$ & 17,2 \\
\hline & SDM & 45,1 & SDM & 47,8 & SDM & 24,6 \\
\hline \multirow{3}{*}{$\begin{array}{l}\text { Mudança climática - uso do solo e } \\
\text { mudança no uso do solo }\left(\mathrm{kg} \mathrm{CO}_{2} \mathrm{eq}\right)\end{array}$} & $\mathrm{MD}$ & 36,1 & CIM & 31,2 & CIM & 41,9 \\
\hline & CIM & 27,5 & $\mathrm{RC}$ & 20,7 & $\mathrm{RC}$ & 28,3 \\
\hline & SDM & 36,5 & SDM & 48,0 & SDM & 29,8 \\
\hline \multirow{3}{*}{ Ecotoxicidade em água doce (CTUe) } & CIM & 61,6 & CIM & 48,1 & CIM & 57,3 \\
\hline & $\mathrm{RC}$ & 34,7 & $\mathrm{RC}$ & 32,5 & $\mathrm{RC}$ & 39,4 \\
\hline & SDM & 3,6 & SDM & 19,4 & SDM & 3,3 \\
\hline \multirow{3}{*}{ Eutrofização marinha ( $\mathrm{kg} \mathrm{N}$ eq) } & CIM & 49,9 & CIM & 42,5 & CIM & 56,8 \\
\hline & $\mathrm{RC}$ & 19,8 & $\mathrm{RC}$ & 20,3 & $\mathrm{RC}$ & 27,6 \\
\hline & SDM & 30,3 & SDM & 37,3 & SDM & 15,6 \\
\hline \multirow{3}{*}{ Eutrofização em água doce (kg P eq) } & CIM & 49,2 & $\mathrm{RC}$ & 45,1 & $\mathrm{RC}$ & 51,7 \\
\hline & $\mathrm{RC}$ & 46,7 & CIM & 39,7 & CIM & 44,7 \\
\hline & SDM & 4,0 & SDM & 15,2 & SDM & 3,6 \\
\hline \multirow{3}{*}{ Eutrofização terrestre (mol N eq) } & CIM & 46,4 & CIM & 40,7 & CIM & 56,4 \\
\hline & $\mathrm{RC}$ & 15,8 & $\mathrm{RC}$ & 16,6 & $\mathrm{RC}$ & 23,5 \\
\hline & SDM & 37,7 & SDM & 42,7 & SDM & 20,1 \\
\hline \multirow{3}{*}{ Toxicidade humana, câncer (CTUh) } & CIM & 48,5 & $\mathrm{RC}$ & 40,1 & $\mathrm{RC}$ & 48,7 \\
\hline & $\mathrm{RC}$ & 41,9 & CIM & 38,7 & CIM & 46,2 \\
\hline & SDM & 9,6 & SDM & 21,3 & SDM & 5,1 \\
\hline
\end{tabular}




\begin{tabular}{|c|c|c|c|c|c|c|}
\hline \multirow[b]{2}{*}{ Categoria de impacto } & \multicolumn{2}{|l|}{ Projeto 1} & \multicolumn{2}{|l|}{ Projeto 2} & \multicolumn{2}{|l|}{ Projeto 3} \\
\hline & $\begin{array}{l}\text { Insumos } \\
\text { relevantes }\end{array}$ & $\%$ & $\begin{array}{l}\text { Insumos } \\
\text { relevantes }\end{array}$ & $\%$ & $\begin{array}{l}\text { Insumos } \\
\text { relevantes }\end{array}$ & $\%$ \\
\hline \multirow{3}{*}{$\begin{array}{l}\text { Toxicidade humana, não câncer } \\
\text { (CTUh) }\end{array}$} & CIM & 55,2 & CIM & 43,6 & CIM & 53,6 \\
\hline & $\mathrm{RC}$ & 33,3 & $\mathrm{RC}$ & 31,5 & $\mathrm{RC}$ & 39,5 \\
\hline & SDM & 11,6 & SDM & 24,9 & SDM & 6,9 \\
\hline \multirow{3}{*}{$\begin{array}{l}\text { Radiação ionizante, saúde humana } \\
\left(\mathrm{kBq} \mathrm{U}^{235}\right)\end{array}$} & CIM & 41,5 & CIM & 39,0 & CIM & 49,0 \\
\hline & $\mathrm{RC}$ & 24,3 & $\mathrm{RC}$ & 27,3 & $\mathrm{RC}$ & 35,0 \\
\hline & SDM & 34,2 & SDM & 33,7 & SDM & 16,0 \\
\hline \multirow{3}{*}{ Uso do solo (Item(s)) } & MD & 71,2 & MD & 26,6 & CIM & 27,6 \\
\hline & CIM & 14,8 & CIM & 25,0 & MD & 24,4 \\
\hline & SDM & 14,0 & SDM & 48,4 & SDM & 48,0 \\
\hline \multirow{3}{*}{ Depleção de ozônio (kg CFC-11eq) } & CIM & 56,7 & CIM & 44,5 & CIM & 52,1 \\
\hline & $\mathrm{RC}$ & 39,5 & $\mathrm{RC}$ & 37,1 & $\mathrm{RC}$ & 44,2 \\
\hline & SDM & 3,9 & SDM & 18,4 & SDM & 3,7 \\
\hline \multirow{3}{*}{ Material particulado (PM2.5) } & $\mathrm{AR}$ & 95,4 & $\mathrm{AR}$ & 70,4 & $\mathrm{AR}$ & 94,9 \\
\hline & $\mathrm{RC}$ & 3,1 & BLC & 25,5 & $\mathrm{RC}$ & 4,5 \\
\hline & SDM & 1,5 & SDM & 4,1 & SDM & 0,6 \\
\hline \multirow{3}{*}{$\begin{array}{l}\text { Formação fotoquímica de ozônio- } \\
\text { saúde humana (kg COVNM eq) }\end{array}$} & CIM & 41,9 & CIM & 37,1 & CIM & 54,0 \\
\hline & MD & 14,3 & $\mathrm{RC}$ & 14,2 & $\mathrm{RC}$ & 21,1 \\
\hline & SDM & 43,9 & SDM & 48,7 & SDM & 25,0 \\
\hline \multirow{3}{*}{ Uso de recursos, fósseis (MJ) } & CIM & 31,9 & CIM & 28,4 & CIM & 41,1 \\
\hline & $\mathrm{RC}$ & 18,4 & $\mathrm{RC}$ & 19,6 & $\mathrm{RC}$ & 28,9 \\
\hline & SDM & 49,7 & SDM & 52,0 & SDM & 30,0 \\
\hline \multirow{3}{*}{$\begin{array}{l}\text { Uso de recursos, minerais e metais } \\
(\mathrm{kg} \mathrm{Sb} \text { eq) }\end{array}$} & $\mathrm{RC}$ & 47,6 & $\mathrm{RC}$ & 40,2 & $\mathrm{RC}$ & 70,4 \\
\hline & CA50 & 27,1 & CA60 & 23,2 & CIM & 19,2 \\
\hline & SDM & 25,3 & SDM & 36,6 & SDM & 10,5 \\
\hline \multirow{3}{*}{ Uso de água $\left(\mathrm{m}^{3}\right)$} & CIM & 52,6 & CIM & 42,2 & CIM & 54,3 \\
\hline & $\mathrm{RC}$ & 29,6 & $\mathrm{RC}$ & 28,5 & $\mathrm{RC}$ & 37,3 \\
\hline & SDM & 17,7 & SDM & 29,2 & SDM & 8,4 \\
\hline
\end{tabular}

Legenda: CIM: Cimento Portland; AR: areia: CA50: aço CA-50; CA60: aço CA-60; MD: madeira maciça; RC: revestimento cerâmico; BLC: blocos de concreto; CAL: Cal hidratada; SDM: soma dos impactos dos demais insumos. Fonte: Autores.

Conforme a Tabela 4, dentre os materiais de construção analisados, o cimento Portland é o que gera maior dano ao meio ambiente. Das 19 categorias de impacto ambiental negativos, o cimento Portland é o maior contribuinte em 17 categorias dos projetos 1 e 2 e em 18 categorias do projeto 3. O segundo maior contribuinte é o revestimento cerâmico para pisos e paredes, respondendo pelo segundo lugar em 13 categorias do projeto 1 e 14 e 15 categorias dos projetos 2 e 3, respectivamente. Os demais insumos observados como relevantes em algumas categorias de impacto negativo são: Aços CA-50 e CA-60, cal, blocos de concreto, areia e madeira maciça.

Observa-se ainda que os maiores impactos ambientais negativos potenciais provem de insumos que utilizam fornos intensivamente em algum processo de fabricação. No caso específico do cimento Portland, as maiores emissões ocorrem na obtenção do clínquer. Segundo Moretti e Caro (2017), os tipos de cimento Portland que tem a proporção menor de clínquer em relação ao seu peso, apresentam emissões mais baixas, devido a menor utilização de energia. No caso do revestimento cerâmico, as maiores emissões ocorrem no forno, devido ao consumo de gás natural e das emissões associadas à sua combustão, como mencionam Ibáñez-Forés et al. (2011).

Em relação à acidificação, os insumos que mais contribuem para esta categoria de impacto, são o cimento Portland e o revestimento cerâmico. Nos processos de produção, há emissões que reagem com a água presente na atmosfera, colaborando para a formação de chuvas ácidas. As emissões ocorrem nos processos de obtenção do clínquer e nos fornos das cerâmicas. Nestas etapas produtivas, ocorre maior emissões de óxidos de enxofre $(\mathrm{SOx})$, amônia $\left(\mathrm{NH}_{3}\right), \mathrm{N}_{2} \mathrm{O}$; dióxido de enxofre $\left(\mathrm{SO}_{2}\right)$ e 
óxidos de nitrogênio $\left(\mathrm{NO}_{\mathrm{x}}\right)$, que ao reagir com a água presente na atmosfera, aumenta a acidez da água da chuva (Devi et al., 2017).

Os impactos negativos conexos às mudanças climáticas são relacionados a liberação de gases do efeito estufa, principalmente, $\mathrm{o}_{2}$. Nas quatro categorias de impactos referentes às mudanças climáticas, o cimento Portland é o insumo mais significativo, a exceção ocorre no projeto1 na categoria mudança climática referente ao uso do solo e a mudança no uso do solo. Neste caso, o material mais significativo é a madeira. Tal fato ocorre devido ao maior uso de madeira por $\mathrm{m}^{2}$ de área construída, porque no projeto 1 a solução da cobertura em telhas cerâmicas demanda estrutura de madeira. Para efeito comparativo entre os projetos, o projeto 1 demanda 4,1 vezes mais o volume de madeira por $\mathrm{m}^{2}$ de área construída que o projeto 2 e três vezes mais que o projeto 3 .

O segundo insumo mais representativo é o revestimento cerâmico. Apenas no projeto 1, na categoria mudança climática - combustível fóssil, o segundo insumo mais representativo é a cal. As emissões de ambos os materiais de construção vêm do uso de fornos. Em termos absolutos, a categoria de impacto mudanças climáticas é a quarta categoria com os maiores valores absolutos nos três projetos de referência.

Nas categorias de impacto ecotoxicidade em água doce, eutrofização marinha, eutrofização em água doce e eutrofização terrestre, os materiais de construção que mais contribuem para estes impactos são o cimento Portland e o revestimento cerâmico. Parte significativa destas emissões está relacionada à produção e ao uso de combustíveis fósseis. Nesses processos há geração de efluentes, além disso, os subprodutos gerados na combustão são lançados na atmosfera e carreados para o solo, chegando aos corpos hídricos.

Os compostos orgânicos não voláteis que causam toxicidade em humanos são formados através de reações fotoquímicas na atmosfera, relacionadas às emissões de flúor e de seus compostos inorgânicos, barita e bário e muitos metais pesados como o vanádio, assim como, apontam Devi et al. (2017). Os insumos que mais contribuem para estas emissões são o cimento Portland e o revestimento cerâmico, sobretudo na produção do clínquer e no uso de fornos.

$\mathrm{Na}$ categoria radiação ionizante, os dois insumos que mais cooperam para esta categoria de impacto são o cimento Portland e o revestimento cerâmico. Pois, segundo Beck (1989), durante a sua queima em fornos os combustíveis fosseis emitem partículas radioativas. Estas emissões ainda podem estar relacionadas ao uso de energias geradas em usinas atômicas, como afirmam Fazio et al. (2018).

Quanto aos impactos negativos relativos ao uso do solo, os insumos que mais contribuem com esta categoria nos projetos 1 e 2 são a madeira maciça e o cimento Portland. No projeto 3 esta ordem é invertida, porque nesse projeto, apesar do maior número de pavimentos, há um reaproveitamento mais frequente das formas de madeira, associado à ausência de cobertura com estrutura de madeira. Em termos de valor absoluto, esta categoria é a que tem o maior valor, tanto na extração de madeira quanto à mineração. Além de causar mudanças significativas adversas ao uso do solo, essas atividades requerem grandes áreas, acarretando muitos prejuízos ao meio ambiente.

Na categoria depleção de ozônio, as emissões ocorrem na fabricação do clínquer e no uso de fornos para o revestimento cerâmico. Dentre todas as categorias estudadas, essa apresenta os menores valores absolutos de impacto negativo, embora, a sua vida útil média na atmosfera seja de 52 anos. Neste período, o gás CFC-11 permanece degradando a camada de ozónio, potencializando, desse modo, seu dano ambiental, assim como menciona Chipperfield (2015). Como esta categoria de impacto é medida em termos de massa equivalente de CFC-11, pode haver emissões de outros gases com o mesmo dano ambiental, mas com vida média útil maior que o CFC-11, agravando ainda mais o problema.

A extração de areia é a atividade que mais contribui para emissão de material particulado nos três projetos de referência. Nos projetos 1 e 3, o segundo insumo mais significativo é o revestimento cerâmico. No projeto 2 são os blocos estruturais de 
concreto que possuem areia na sua composição. Segundo Minguillón et al. (2009), as maiores emissões de material particulado, na manufatura do revestimento cerâmico ocorrem nos processos de fabricação e não na extração de matérias primas.

Os dois insumos mais relevantes quanto ao uso de recursos fósseis são o cimento Portland e o revestimento cerâmico. Este recurso é utilizado no transporte e no forno. De acordo com Stafford et al. (2016) o consumo mais significativo ocorre nos fornos.

No caso específico do cimento Portland, há predominância do uso de combustíveis fósseis (coque de petróleo, carvão mineral, gás natural e diesel), entretanto na visão de Madlool et al. (2011) podem ser utilizados outros combustíveis, a exemplo de óleo e combustíveis alternativos, como os resíduos ou biomassa. Para o revestimento cerâmico o combustível predominante é o gás natural, como citam Ibáñez-Forés et al. (2011). Em termos de valores absolutos esta é a segunda categoria de impacto negativo mais relevante.

As emissões referentes à formação fotoquímica de ozônio - saúde humana, estão relacionadas à diminuição da concentração de ozônio troposférico, em consequência das emissões de compostos orgânicos voláteis não metálicos (COVNM). Nos três projetos, o cimento Portland é o insumo mais relevante na contribuição dessas emissões. No Projeto 1, o segundo insumo mais relevante é a madeira maciça e nos demais projetos é o revestimento cerâmico. Conforme Suárez et al. (2016), os COVNM são liberados principalmente na queima de combustíveis fosseis.

Quanto ao uso de recursos minerais e metais, para os três projetos avaliados, o insumo mais relevante nesta categoria é o revestimento cerâmico. Nos projetos 1 e 2 são os aços CA-50 e CA-60 e no projeto 3 é o cimento Portland. No projeto 3 por se tratar de uma edificação de 18 pavimentos com peças em concreto armado robustas para resistir a ação do vento e outros esforços estruturais, tal situação demanda um incremento nas peças estruturais, o que eleva significativamente o consumo de cimento Portland em relação ao de aço.

Quanto ao uso da água este impacto negativo considera a água incorporada ao produto, bem como os impactos causados pela deposição de efluentes em corpos hídricos. Os insumos que mais colaboraram para esta categoria foram o cimento Portland e o revestimento cerâmico. No caso do cimento Portland, o maior uso da água ocorreu de forma indireta, na fabricação do clínquer. Situação também citada por Gerbens-Leenes et al. (2018). Já na produção de cerâmica, os autores Ibáñez-Forés et al. (2011) relatam que a maior parte do consumo de água é incorporada ao produto nos processos.

\section{Conclusão}

A ACV permitiu identificar quais tipos de habitação e insumos causam os maiores impactos ambientais negativos por $\mathrm{m}^{2}$ de construção habitacional, averiguando-se a etapa do ciclo de vida dos materiais de construção que provoca maiores danos ao meio ambiente, estão associados ao uso de fornos em seus processos produtivos, em termos absolutos os maiores impactos são relacionados ao uso do solo, uso de combustíveis fosseis, ecotoxicidade em água doce e mudanças climáticas $\left(\mathrm{CO}_{2}\right)$.

O projeto de referência 3, com maior número de pavimentos, foi o que causou maiores impactos negativos por $\mathrm{m}^{2} \mathrm{de}$ área construída. Entretanto, não foi possível atestar que as edificações com muitos pavimentos acarretam mais danos ambientais do que as construções de menor porte, uma vez que a obtenção de áreas e obras de infraestrutura também podem gerar impactos negativos significativos.

Quanto aos insumos, o cimento Portland e o revestimento cerâmico são os que geram impactos ambientais negativos potenciais, sobretudo na obtenção do clínquer e no uso de fornos no processo de fabricação. O uso de cimento Portland e revestimentos cerâmicos pode ser minimizado ainda na fase de planejamento da obra, desde o desenvolvimento de projetos arquitetônicos, reduzindo-se a relação entre o perímetro das paredes e a área construída. Além disto, pode-se fazer estudos comparativos de ACV para substituir, sempre que possível, as alvenarias convencionais por painéis e divisórias, assim como, o 
tipo de revestimento. Pode-se ainda adotar soluções estruturais que minimizem o consumo de cimento Portland, bem como adotar paginação de cerâmicas que reduzam os recortes.

Estas informações auxiliam aos gestores da construção civil na tomada de decisão com foco na sustentabilidade ambiental, desde a concepção de projetos de arquitetura a escolha da solução estrutural, métodos construtivos, materiais de acabamento e os processos de fabricação dos insumos.

\section{Referências}

Aktas, Can B., Bilec, \& Melissa M. (2011). Impact of lifetime on US residential building LCA results. The International Journal Of Life Cycle Assessment, 17(3), 337-349. http://dx.doi.org/10.1007/s11367-011-0363-x.

Asadollahfardi, G., Asadi, M., \& Karimi, S. (2015). Life-Cycle Assessment of Construction in a Developing Country. Environmental Quality Management, 24(4), 11-21. Wiley. http://dx.doi.org/10.1002/tqem.21398.

ABNT. (2014). NBR ISO 14040: Gestão ambiental - Avaliação do ciclo de vida - Princípios e estrutura.

ABNT. (2013). NBR 15575-1: Edificações Habitacionais: Desempenho: Parte 1: Requisitos gerais.

Azevedo, L. D. de, Geraldi, M. S., \& Ghisi, E. (2020). Avaliação do Ciclo de Vida de diferentes envoltórias para habitações de interesse social em Florianópolis. Ambiente Construído, 20(4), 123-141. http://dx.doi.org/10.1590/s1678-86212020000400463.

Beck, H. L. (1989). Radiation exposures due to fossil fuel combustion. International Journal Of Radiation Applications And Instrumentation. Part C. Radiation Physics And Chemistry, 34(2), 285-293. http://dx.doi.org/10.1016/1359-0197(89)90236-1.

Lei n ${ }^{\circ} 11.514$, de 13 de agosto de 2007 (2007). Dispõe sobre as diretrizes para a elaboração e execução da Lei Orçamentária de 2008 e dá outras providências. Brasília, DF: Diário Oficial da União.

Brasil. Ministério da Economia. (2020) Relatório de Avaliação: programa minha casa minha vida. Programa Minha Casa Minha Vida. https://www.gov.br/cgu/ptbr/assuntos/noticias/2021/04/cgu-divulga-prestacao-de-contas-do-presidente-da-republica-de-2020/relatorio-de-avaliacao-pmcmv.pdf/view.

Caixa Econômica Federal (2017). SINAPI - Sistema Nacional de Pesquisa de Custos e Índices da Construção Civil. Demonstrações de Uso: Fichas técnicas. https://www.caixa.gov.br/site/paginas/downloads.aspx.

Caixa Econômica Federal (2021). SINAPI - Sistema Nacional de Pesquisa de Custos e Índices da Construção Civil. https://www.caixa.gov.br/poderpublico/modernizacao-gestao/sinapi/Paginas/default.aspx.

Caixa Econômica Federal (2020). SINAPI - Sistema Nacional de Pesquisa de Custos e Índices da Construção Civil. Metodologias e Conceitos. https://www.caixa.gov.br/Downloads/sinapi-manual-de-metodologias-e-conceitos/Livro1_SINAPI_Metodologias_e_Conceitos_8_Edicao.pdf.

Chipperfield, Martyn P. (2015). Global Atmosphere - The Antarctic Ozone Hole. Issues In Environmental Science And Technology, 1-33. Royal Society of Chemistry. http://dx.doi.org/10.1039/9781782622178-00001

Ciroth, A., Noi, C. Di, Lohse, T., Srocka, M. OpenLCA 1.9: Comprehensive user manual. Berlin: Greendelta, 2019. 116 p. http://www.openlca.org/learning/.

Devi, K. S., Lakshmi, V. V., Alakanandana, A. (2017). Impacts of cement industry on environment: an overview. Asia Pacific Journal Of Research. 1, 156-161. https://www.researchgate.net/publication/323029097_Impacts_of_Cement_Industry_on_Environment_-_An_Overview.

Fazio, S., Castellani, V., Sala, S., Schau, E., Secchi, M., Zampori, L., Diaconu, E. (2018). Supporting information to the characterisation factors of recommended EF Life Cycle Impact Assessment method: new models and differences with ilcd. Jrc Technical Reports. Inspra, 1-42. https://publications.jrc.ec.europa.eu/repository/handle/JRC109369.

Fundação Getúlio Vargas (2018). Análise das Necessidades habitacionais e suas tendências para os próximos dez anos https://www.abrainc.org.br/estudos/2018/10/17/abrainc-e-fgv-apresentam-estudo-da-analise-das-necessidades-habitacionais-e-suas-tendencias-para-osproximos-dez-anos/. Acesso em: $26 \mathrm{dez} .2021$.

Gerbens-Leenes, P. W., Hoekstra, A. Y., \& Bosman, R. (2018). The blue and grey water footprint of construction materials: steel, cement and glass. Water Resources And Industry, 19, 1-12. http://dx.doi.org/10.1016/j.wri.2017.11.002.

GREENDELTA. OpenLCA. 2020. http://www.openlca.org/.

Guggemos, A. A., \& Horvath, A. (2005). Comparison of Environmental Effects of Steel- and Concrete-Framed Buildings. Journal of Infrastructure Systems, 11(2), 93-101. http://dx.doi.org/10.1061/(asce)1076-0342(2005)11:2(93).

Heede, P. Van D., Belie, N. De. (2012). Environmental impact and life cycle assessment (LCA) of traditional and 'green' concretes: literature review and theoretical calculations. Cement And Concrete Composites, 34(4), 431-442. http://dx.doi.org/10.1016/j.cemconcomp.2012.01.004. 
Ibáñez-Forés, V., Bovea, M.-D., \& Simó, A. (2011). Life cycle assessment of ceramic tiles. Environmental and statistical analysis. The International Journal Of Life Cycle Assessment, 16(9), 916-928. http://dx.doi.org/10.1007/s11367-011-0322-6.

Instituto Brasileiro de Geografia e Estatística (2015). Pesquisa Nacional por Amostra de Domicílios - Acesso à internet e à televisão e posse de telefone móvel celular para uso pessoal. p. 25. https://biblioteca.ibge.gov.br/visualizacao/livros/liv99054.pdf.

Ingrao, C., Messineo, A., Beltramo, R., Yigitcanlar, T., \& Ioppolo, G. (2018). How can life cycle thinking support sustainability of buildings? Investigating life cycle assessment applications for energy efficiency and environmental performance. Journal Of Cleaner Production, 201, 556-569. http://dx.doi.org/10.1016/j.jclepro.2018.08.080.

Kamali, M., Hewage, K., \& Sadiq, R. (2019). Conventional versus modular construction methods: a comparative cradle-to-gate lca for residential buildings. Energy and Buildings, 204, 109479. http://dx.doi.org/10.1016/j.enbuild.2019.109479.

Madlool, N. A., Saidur, R., Hossain, M. S., \& Rahim, N. A. (2011). A critical review on energy use and savings in the cement industries. Renewable And Sustainable Energy Reviews, 15(4), 2042-2060. http://dx.doi.org/10.1016/j.rser.2011.01.005.

Mattos, A. D. (2006). Como preparar orçamentos de obras: dicas para orçamentistas, estudos de caso, exemplos. (4a ed.), Pini. 281 p.

Medeiros, L. M., Durante, L. C., Callejas, I. J. A. (2018). Contribuição para a avaliação de ciclo de vida na quantificação de impactos ambientais de sistemas construtivos. Ambiente Construído, 18(2), 365-385. http://dx.doi.org/10.1590/s1678-86212018000200259.

Minguillón, M. C., Monfort, E., Querol, X., Alastuey, A., Celades, I., \& Miró, J. V. (2009). Effect of ceramic industrial particulate emission control on key components of ambient PM10. Journal Of Environmental Management, 90(8), 2558-2567. http://dx.doi.org/10.1016/j.jenvman.2009.01.016.

Montes, M. A. T. (2016). Abordagem Integrada no Ciclo de Vida de Habitações de Interesse Social considerando mudanças climáticas. 573 f. Tese (Doutorado em Engenharia Civil) - Programa de Pós-Graduação em Engenharia Civil, Universidade Federal de Santa Catarina, Florianópolis, 2016.

Moretti, L., Caro, S. (2017). Critical analysis of the Life Cycle Assessment of the Italian cement industry. Journal Of Cleaner Production, 152, 198-210. http://dx.doi.org/10.1016/j.jclepro.2017.03.136.

Nematchoua, M. K., Teller, J., \& Reiter, S. (2019). Statistical life cycle assessment of residential buildings in a temperate climate of northern part of Europe. Journal of Cleaner Production. 229, 621-631. http://dx.doi.org/10.1016/j.jclepro.2019.04.370.

Ortiz, Oscar, Castells, Francesc, Sonnemann, Guido. (2009). Sustainability in the construction industry: a review of recent developments based on lca. Construction And Building Materials, 23(1), 28-39. http://dx.doi.org/10.1016/j.conbuildmat.2007.11.012.

Oyarzo, J., \& Peuportier, B. (2014). Life cycle assessment model applied to housing in Chile. Journal Of Cleaner Production, 69, 109-116. http://dx.doi.org/10.1016/j.jclepro.2014.01.090.

Stafford, F. N., Raupp-Pereira, F., Labrincha, J. A., \& Hotza, D. (2016). Life cycle assessment of the production of cement: a brazilian case study. Journal Of Cleaner Production, 137, 1293-1299. http://dx.doi.org/10.1016/j.jclepro.2016.07.050.

Suárez, Sindy, Roca, Xavier, Gasso, Santiago. (2016). Product-specific life cycle assessment of recycled gypsum as a replacement for natural gypsum in ordinary Portland cement: application to the spanish context. Journal Of Cleaner Production, 117, 150-159. http://dx.doi.org/10.1016/j.jclepro.2016.01.044.

Tae, S., Baek, C., \& Shin, S. (2011). Life cycle CO2 evaluation on reinforced concrete structures with high-strength concrete. Environmental Impact Assessment Review, 31(3), 253-260. http://dx.doi.org/10.1016/j.eiar.2010.07.002. 